\section{Hypothermia and Coagulation Defects in the Newborn}

Hypothermia in infants is associated with a risk of haemorrhage, especially into the lungs or brain. Mann and Elliott (1957) studied 14 babies who developed the syndrome of neonatal cold injury. 8 of these babies died, and in 5 , the postmortem finding was 'haemorrhagic pneumonia' or massive pulmonary haemorrhage. However, haemorrhage in other tissues was not a conspicuous feature. One of the babies who recovered was treated with fresh frozen plasma which may have prevented haemorrhage.

Johansson and Nilsson (1964) found thrombocytopenia in dogs subjected to cooling to $20^{\circ} \mathrm{C}$. They also found that hypothermia was associated with a decrease in factors I, II, and VII, with increased fibrinolytic activity. They concluded that hypothermia induced coagulation defects through the mechanism of intravascular coagulation, with a decrease of fibrinogen due to consumption of this factor in the coagulation process.

Recently, Kattlove and Alexander (1970) found one explanation for the prolonged bleeding time found when the site of a surgical incision was chilled. They noted that platelet aggregation was inhibited by cold; when the temperature of the experimental procedure was reduced to $2-4^{\circ} \mathrm{C}$ there was no platelet aggregation.

There has been very little systematic study of the effect of hypothermia on the coagulation status of the newborn human infant. Much of the work that has been done concerns the experimental animal. The following study was performed in order to obtain information about the newborn infant. It was conducted during a time when insufficient emphasis was placed on maintenance of body heat; consequently some infants dropped their body temperatures to $34^{\circ} \mathrm{C}$ within a matter of an hour or two of birth. This situation no longer happens in this hospital because of the active steps taken to prevent hypothermia. For instance, in 1971 only 11 infants dropped their rectal temperature to $34{ }^{\circ} \mathrm{C}$ during the first day of life, as compared to 61 , four years ago.

\section{Cases and Methods}

The coagulation status of 190 newborn babies who were consecutive admissions to the Special Care Unit of the Cardiff Maternity Hospital was studied. 19 babies or $10 \%$ of the total were found to have a rectal temperature of $34^{\circ} \mathrm{C}$ or less shortly after birth.

These hypothermic babies were matched for sex, birthweight, gestation, and one-minute Apgar score, with 19 babies whose rectal temperature during the first day of life was $35^{\circ} \mathrm{C}$ or more. The blood coagulation tests used were as follows: the thrombotest as a guide to the prothrombin complex level and performed as previously described by Gray, Ackerman, and Fraser (1968) uncorrected for haemoglobin levels; platelets were counted using phase contrast microscopy; the kaolin cephalin clotting time was adapted from the partial thromboplastin time by the addition of kaolin (Proctor and Rapaport, 1961) and performed as follows. To $0.05 \mathrm{ml}$ test plasma $0.025 \mathrm{ml}$ of $0.5 \%$ kaolin was added. One minure 45 seconds after the addition of the kaolin, $0.05 \mathrm{ml}$ platelet substitute (Thrombofax Ortho) was added. After a further 15 seconds, $0.05 \mathrm{ml} \mathrm{M} / 40$ calcium chloride was added to the mixture.

The time taken for this mixture to clot is termed the kaolin cephalin clotting time (KCCT). The result for the test is expressed as a ratio by dividing the result obtained for each test plasma by the result obtained from the blood of a healthy adult volunteer.

The thrombin clotting time (TCT) was adapted from the thrombin time as described by Dacie and Lewis (1968). To $0.05 \mathrm{ml}$ plasma to be tested, $0.05 \mathrm{ml}$ normal saline and $0.05 \mathrm{ml}$ thrombin are added. The thrombin was previously diluted to give a standard time of 15 seconds with a healthy adult control plasma. A stopwatch was started on addition of the thrombin to the mixture. The time taken for the mixture to form a clot is termed the 'thrombin clotting time' and is expressed as a ratio by dividing the thrombin clotting time in seconds of each test plasma by 15 .

Fibrin degradation products were measured by using the Burroughs Wellcome test kit which is based on the methods of fibrin degradation product level measurements of Murakami et al. (1965) and Merskey, Kleiner, and Johnson (1966).

Blood gases were estimated on Astrup microequipment. Blood for the coagulation times and fibrin degradation products was obtained by femoral venepuncture. The blood for the clotting tests was placed in tubes containing $3 \cdot 8 \%$ trisodium citrate $(9: 1$ volumes) and for the fibrin degradation products into tubes containing aprotinia.

\section{Results}

Tables I and II showed that in the hypothermic group of infants all the tests of coagulation are more abnormal than in the control group. The only significant difference is in the thrombin clotting time where $P<0.05$. The levels of fibrin degradation products were higher in the cold babies; thus the presence of circulating anticoagulants, probably the fibrin degradation products, is the likely explanation for the abnormally prolonged thrombin clotting times.

It should be noted that 7 of the hypothermic infants died during the perinatal period, but none of the control infants died during this period. 
TABLE I

Relevant Clinical Data Pertaining to Infants in Study

\begin{tabular}{|c|c|c|c|c|c|}
\hline & Sex & $\begin{array}{c}\text { Birthweight } \\
\text { (kg) }\end{array}$ & $\begin{array}{l}\text { Gestation } \\
\text { (wk) }\end{array}$ & $\begin{array}{l}\text { Pregnancy } \\
\text { Complications } \\
\text { (APH, PET) }\end{array}$ & Outcome \\
\hline $\begin{array}{l}19 \text { Control babies, rectal temperature } 35^{\circ} \mathrm{C} \text { or more } \\
\text { Mean } \\
\text { Range }\end{array}$ & $10 M \quad 9 F$ & $\begin{array}{l}2 \cdot 1 \\
1 \cdot 2-4 \cdot 3\end{array}$ & $\begin{array}{l}35 \\
31-40\end{array}$ & 5 & 1 death* \\
\hline $\begin{array}{l}19 \text { Hypothermic babies, rectal temperature } 34^{\circ} \mathrm{C} \text { or less } \\
\text { Mean } \\
\text { Range }\end{array}$ & $10 \mathrm{M} 9 \mathrm{~F}$ & $\begin{array}{l}2 \cdot 1 \\
1 \cdot 1-4 \cdot 2\end{array}$ & $\begin{array}{l}35 \\
30-41+\end{array}$ & 4 & 7 deaths \\
\hline
\end{tabular}

^Late death-6 weeks.

TABLE II

Statistical Analysis of Coagulation Tests Performed on 2 Groups of Infants

\begin{tabular}{|c|c|c|c|c|}
\hline & Control Group & \multicolumn{3}{|c|}{ Hypothermic Group } \\
\hline Mean and SEM & Total & Total & Dead & Alive \\
\hline $\begin{array}{l}\text { Apgar } \\
\text { Base deficit } \\
\text { Platelets } 10^{3} / \mathrm{mm}^{3} \\
\text { Kaolin cephalin } \\
\text { clotting time (ratio) } \\
\text { Thrombin clotting } \\
\text { time (ratio) } \\
\text { Thrombotest (\%) } \\
\text { Mean } \\
\text { Range }\end{array}$ & $\begin{array}{c}4 \cdot 7 \pm 0 \cdot 6 \\
(n=19) \\
+3 \cdot 1 \pm 1 \cdot 04 \\
(n=16) \\
154 \cdot 8 \pm 9 \cdot 2 \\
(n=19) \\
1 \cdot 3 \pm 0 \cdot 04 \\
(n=19) \\
1 \cdot 3 \pm 0 \cdot 09 \\
(n=19) \\
26 \cdot 6 \pm 7 \cdot 95 \\
(n=19) \\
10 \cdot 08 \\
(n=4) \\
2 \cdot 5 \pm 20\end{array}$ & $\begin{array}{c}3 \cdot 9 \pm 0 \cdot 72 \\
(n=19) \\
+8 \cdot 2 \pm 1 \cdot 28 \\
(n=19) \\
122 \cdot 5 \pm 9 \cdot 8 \\
(n=17) \\
1 \cdot 5 \pm 0 \cdot 10 \\
(n=19) \\
2 \cdot 27 \pm 0 \cdot 39 \\
(n=19) \\
18 \cdot 9 \pm 2 \cdot 02 \\
(n=19) \\
140 \\
(n=3) \\
80-320\end{array}$ & $\begin{array}{c}2 \cdot 4 \pm 0 \cdot 92 \\
(n=7) \\
+9 \cdot 0 \pm 1 \cdot 98 \\
(n=7) \\
103 \quad \pm 5 \cdot 28 \\
(n=7) \\
1 \cdot 3 \pm 0 \cdot 07 \\
(n=7) \\
2 \cdot 6 \pm 0 \cdot 97 \\
(n=7) \\
14 \cdot 1 \pm 3 \cdot 2 \\
(n=7) \\
140 \\
(n=3) \\
8-320\end{array}$ & $\begin{array}{c}4 \cdot 8 \pm 0 \cdot 93 \\
(n=12) \\
+7 \cdot 7 \pm 1 \cdot 71 \\
(n=12) \\
132 \cdot 5 \pm 14 \cdot 16 \\
(n=12) \\
1 \cdot 6 \pm 0 \cdot 16 \\
(n=12) \\
2 \cdot 1 \pm 0 \cdot 30 \\
(n=12) \\
21 \cdot 4 \pm 2 \cdot 2 \\
(n=12) \\
- \\
-\end{array}$ \\
\hline
\end{tabular}

*P $<0.05$ for thrombin clotting time between controls and hypothermic babies.

tNumbers too small for statistical analysis.

Note: Fibrin degradation products: numbers too small for statistical analysis.

Permission for necropsy was given for 6 of the 7 hypothermic infants who died; 3 of these died of massive cerebral haemorrhage, one from congenital abnormalities, one from the idiopathic respiratory distress syndrome, and one from bronchopneumonia. The baby for whom necropsy permission was refused had a bulging anterior fontanelle and falling haemoglobin and haematocrit which suggests this baby also died with a cerebral haemorrhage.

Histological examination and specific staining for the presence of antemortem fibrin deposits using phosphotungstic acid haematoxylin revealed evidence of intravascular fibrin in one or more vital organs of 5 of the infants, i.e. liver, lung, brain, spleen, kidney, etc., no deposits of fibrin being found at necropsy of the control infant who died at 6 weeks of age. This is supportive evidence for a consumption coagulopathy occurring during life in these infants and aggravated by hypothermia.

\section{Discussion}

In a series of 14 infants suffering from the effects of hypothermia, Mann and Elliott (1957) reported 8 deaths. It was found that pulmonary haemorrhage was the major cause of death in $\mathbf{5}$ of the babies. In 1963, Arneil and Kerr found cerebral haemorrhage in $13 \%$ of infants dying from cold exposure. No coagulation tests were performed, however.

More recently, Chessells and Wigglesworth (1970), reporting on the necropsy findings of 5 babies with secondary haemorrhagic disease, noted that hypothermia had been recorded before death in 2 of the babies who had died of cerebral haemorrhage. A similar finding to that of Chessells and Wiggles- 
worth (1970) has also been reported by Chadd (1970).

The cause of the intravascular coagulation occurring with hypothermia was suggested by Johansson and Nilsson (1964) to be stagnation of blood, disintegration of red blood cells, and platelets releasing thromboplastin and initiating coagulation. In the present series of hypothermic infants there was a marked thrombocytopenia and coagulation changes of a consumption coagulopathy which was not seen in the control infants whose rectal temperature did not fall below $34^{\circ} \mathrm{C}$. This suggests that the babies may react in a similar way to the animals of Johansson and Nilsson (1964) on exposure to cold. Though the admission rate to the Special Care Unit of our hospital has increased, the number of babies admitted who have a rectal temperature of $34{ }^{\circ} \mathrm{C}$ or less during the first day of life has dropped by more than $70 \%$ over the past 5 years. Deaths of babies with a rectal temperature of $34{ }^{\circ} \mathrm{C}$ or less are similarly reduced. These findings are attributed to the introduction of specific measures to maintain babies' body temperature during procedures such as resuscitation and exchange transfusion.

There are two explanations for the association of cerebral haemorrhage and hypothermia. It is possible that the cerebral haemorrhage is responsible for shock and hypothermia or that the haemorrhage follows a consumption coagulopathy induced by hypothermia. We favour the latter explanation, for hypothermia occurred shortly after birth, usually within 6 hours, and the work of Dyer et al. (1971) suggests that intraventricular haemorrhage is likely to occur after 6 hours.

\section{Summary}

Nineteen infants with a rectal temperature of $34{ }^{\circ} \mathrm{C}$ or less during the first hours of life were studied. They have been matched for age, gestation, and birthweight with 19 healthy babies whose rectal temperatures never fell below $35^{\circ} \mathrm{C}$ on the first days of life. Comparison of the coagulation status of the two groups of infants shows a marked deleterious effect of cold. The aetiology of the coagulation defect has been ascribed to disseminated intravascular coagulation. Such a series is likely to be unique since there are widespread measures throughout this country to prevent the occurrence of hypothermia in the newborn baby.

We thank Miss Susan M. Muxworthy for valuable technical assistance, and Mrs. M. D. Johnson for invaluable secretarial help.

The work was carried out while one of us (M.A.C.) had tenure of a research scholarship from the Wellcome
Trust, and the other (S.M.M.) was in receipt of a grant from the Clinical Research Board of the University Hospital of Wales (Cardiff), Hospital Management Committee.

\section{REFERENCES}

Arneil, G. C., and Kerr, M. M. (1963). Severe hypothermia in Glasgow infants in winter. Lancet, 2, 756.

Chadd, M. A. (1970). Disseminated intravascular coagulation and coagulation defects in the newborn. (Abst.) Archives of Disease in Childhood, 45, 819.

Chessells, J. M., and Wigglesworth, J. S. (1970). Secondary haemorrhagic disease of the newborn. Archives of Disease in Childhood, 45, 539.

Dacie, J. V., and Lewis, S. M. (1968). Practical Haematology, 4th ed., p. 256. Churchill, London.

Dyer, N., Raye, J., Gutberlet, R., Faxelius, G., Swanstrom, S., Brill, A. and Stahlman, M. (1971). European Society for Paediatric Research, Brighton, June, 1971.

Gray, O. P., Ackerman, A., and Fraser, A. J., (1968). Intracranial haemorrhage and clotting defects in low-birth-weight infants. Lancet, 1, 545.

Johansson, B. W., and Nilsson, I. M. (1964). The effect of heparin and $\epsilon$-aminocaproic acid on the coagulation in hypothermic dogs. Acta Physiologica Scandinavica, 60, 267.

Kattlove, H., and Alexander, B. (1970). Effect of cold on bleeding. (Letter.) Lancet, 2, 1359.

Mann, T. P., and Elliott, R. I. K. (1957). Neonatal cold injury due to accidental exposure to cold. Lancet, $1,229$.

Merskey, C., Kleiner, G. J., and Johnson, A. J. (1966). Quantitative estimation of split products of fibrinogen in human serum, relation to diagnosis and treatment. Blood, 28,1 .

Murakami, M., Sekimoto, H., Yasuda, Y. et al. (1965). A new method for the determination of fibrinolytic activity by means of immunoassay of breakdown products of fibrin and fibrinogen. (Japanese.) Fapanese fournal of Clinical Pathology, 13, 542.

Proctor, R. R., and Rapaport, S. I. (1961). The partial thromboplastin time with kaolin: a simple screening test for first stage plasma clotting factor deficiencies. American fournal of Clinical Pathology, 36, 212.

M. A. Chadd, * and O. P. Gray

Department of Child Health, University Hospital, Wales (Cardiff).

\footnotetext{
*Correspondence to Dr. M. A. Chadd.
}

\section{Purpura Necrotica as a Complication of Ventriculoatrial Shunts in Hydrocephalus}

Purpura necrotica (or fulminans) is a rare complication of many acute infectious diseases of children, and has been reported after such conditions as vaccination, varicella, measles, streptococcal infection, and neisserial infection. It is characterized by the sudden appearance of symmetrical areas of cutaneous haemorrhage and superficial necrosis most pronounced on the lower extremities, anaemia, and severe systemic symptoms. Until a decade ago mortality in this condition was of the order of $90 \%$ (Charkes, 1961), but recently with better understanding of some of the underlying vascular and coagulation abnormalities, cures have 